\title{
Arqueologia para etnólogos: colaborações entre arqueologia e antropologia na Amazônia
}

Archeology for ethnologists: Collaborations between Archeology and

Anthropology in the Amazon

\section{Denise Pahl Schaan}

\section{(2) OpenEdition}

Edição electrónica

URL: http://journals.openedition.org/aa/1243

DOI: 10.4000/aa. 1243

ISSN: 2357-738X

\section{Editora}

Programa de Pós-Graduação em Antropologia Social (UnB)

\section{Edição impressa}

Data de publição: 1 dezembro 2014

Paginação: 13-46

ISSN: 0102-4302

\section{Refêrencia eletrónica}

Denise Pahl Schaan, «Arqueologia para etnólogos: colaborações entre arqueologia e antropologia na Amazônia», Anuário Antropológico [Online], v.39 n.2 | 2014, posto online no dia 01 agosto 2017, consultado o 27 abril 2021. URL: http://journals.openedition.org/aa/1243 ; DOI: https://doi.org/ 10.4000/aa. 1243

\section{(c)}

Anuário Antropológico is licensed under a Creative Commons Atribuição-Uso Não-Comercial-Proibição de realização de Obras Derivadas 4.0 International. 


\section{Arqueologia para etnólogos: colaborações entre arqueologia e antropologia na Amazônia}

Denise Pahl Schaan

UFPA

\section{Introdução: arqueologia no Brasil e suas aproximações com a etnologia}

A antropologia como disciplina científica nasceu no Ocidente, no final do século XIX, no contexto do debate sobre a variabilidade étnica humana. Tal debate envolveu, por um lado, monogenistas e uma abordagem de base humanista, com uma perspectiva evolutiva e histórica (etnologia); e, por outro lado, poligenistas, cuja aproximação ao objeto de estudo se deu por meio da craniometria e frenologia (antropologia física) (Adams, 1998; Schwarcz, 1993). Apesar das diferenças metodológicas, ambas as correntes preocupavam-se em explicar as diferenças entre os grupos humanos, tomando como ponto de partida (ou chegada) a civilização europeia e, em especial, a sociedade francesa (Tylor, 1871). O histórico de constituição das disciplinas na Europa, assim como nos Estados Unidos, por meio da formação de sociedades científicas e departamentos universitários, levou a antropologia a percorrer caminhos diversos em cada país em que se estabeleceu (Barth, 2005; Meltzer, 1985).

Nos Estados Unidos, no começo do século XX, Franz Boas, geógrafo e físico alemão cuja visão sobre a cultura advinha da tradição culturalista de Herder, propõe à nascente antropologia desnaturalizar as diferenças entre os grupos humanos, lançando-se, ele mesmo, à tarefa de questionar os dogmas raciais profundamente enraizados no senso comum e na política governamental estadunidense (Boas, 1911; Boas \& Stocking, 1974). Tal tarefa hercúlea só poderia ser levada a efeito a partir de uma perspectiva holística da recente disciplina dedicada ao estudo da experiência humana: a antropologia. Ainda que a tendência para a antropologia nos quatro campos (incluindo a linguística, a etnologia, a antropologia física e a arqueologia) já fosse parte da prática no país, por meio da atuação do Bureau of American Ethnology (Meltzer, 1985), a vitória do projeto de Boas só foi possível graças à criação de cursos de Antropologia nas universidades norte-americanas (Balée, 2009; Boas \& Stocking, 1974). Nas primeiras décadas do século XX, os discípulos de Boas criaram ou instalaram-se em departamentos de antropologia por todo o país, institucionalizando a four-field anthropology. 
No Brasil do final do século XIX e começo do século XX, a disciplina segue as tendências europeias. A antropologia física, dentro do Museu Nacional, do Rio de Janeiro, adota os ensinamentos de Paul Broca, fundador da Sociedade Antropológica de Paris, que desde 1865 vem estabelecendo os métodos e instrumentos para estudar as diferenças raciais (Castro-Faria, 1998). Os estudos arqueológicos, entre 1870 e o final do século, são promovidos ou apoiados principalmente pelos museus Nacional, Botânico do Amazonas, Paraense e Paulista, que amealham grandes coleções de artefatos em sítios arqueológicos, especialmente na Amazônia, por meio dos quais fica caracterizado o passado grandioso do território em comparação com o atraso cultural e físico a que os indígenas da época foram relegados (Ferreira, 2007; Schwarcz, 1993). Etnologia e linguística, dessa maneira, têm a tarefa de identificar os grupos étnico-linguísticos do país antes que desapareçam, dada a inevitabilidade do progresso. Com a arqueologia, essas disciplinas legitimam o avanço das frentes colonizadoras e a prioridade do projeto nacional diante da inevitável assimilação ou desaparecimento dos indígenas (Ferreira, 2009; Santos, 2010).

Se, nesse momento, arqueologia e etnologia são inseparáveis, como indica sua posição dentro dos departamentos dos mencionados museus ou sua presença na grande exposição promovida por Ladislau Netto no Museu Nacional em 1882, posteriormente seguirão caminhos distintos no Brasil.

Na primeira metade do século XX, a arqueologia brasileira se resume a iniciativas isoladas de pesquisadores dispersos pelo país, muitos deles etnólogos e frequentemente ligados a museus (Funari, 2002; Melatti, 1983). Não há um projeto para a arqueologia no país. O papel do Museu Goeldi, durante esse período, limita-se ao apoio eventual a missões estrangeiras, que têm o propósito maior de obter coleções da Ilha de Marajó, sem efetiva contribuição ao desenvolvimento da disciplina no país. Destaca-se nesse contexto Curt Nimuendajú, que, apoiado pelo diretor do museu, Carlos Estevão de Oliveira (Hartmann, 2000), realiza inúmeras viagens pela Amazônia para identificar grupos indígenas e coletar artefatos, ainda que as coleções sejam majoritariamente destinadas ao Museu de Gothenburg (Nimuendajú, 2004; Stenborg, 2009). O próprio Carlos Estevão de Oliveira possui coleção particular de artefatos (Torres, 1937), o que indica a tendência à formação de coleções particulares e uma visão ainda bastante amadora da arqueologia, como é também o caso da coleção de Frederico Barata, com artefatos arqueológicos de Santarém (Barata, 1950).

Os poucos estudos arqueológicos voltam-se, nessa época, para a identificação de sítios a partir de demandas esporádicas que surgem ou limitam-se ao estudo de coleções com um enfoque em história da arte (como em Torres 1930, 
1940). Há iniciativas importantes, mas isoladas, de preservação do patrimônio arqueológico, que se consubstanciam na década de 1950, com a criação de núcleos voltados à pesquisa arqueológica, como o Centro de Ensino e Pesquisas Arqueológicas (Cepa), ligado à Universidade Federal do Paraná, e a Comissão de Pré-História, que se tornaria mais tarde o Instituto de Pré-História da Universidade de São Paulo (Barreto, 1999-2000; Castro-Faria, 1998; Torres, 1937).

A partir de 1934, com a criação da Universidade de São Paulo e da Faculdade de Filosofia, Ciências e Letras, o subcampo sociocultural da antropologia pode enfim se institucionalizar, ainda que não na forma de um departamento próprio, mas por meio da influência de sociólogos e etnólogos europeus, especialmente franceses (Peixoto, 1998), com sua visão da etnologia e da arqueologia como disciplinas separadas. A vinda de missões estrangeiras atinge também a arqueologia a partir do final dos anos 1940 (Barreto, 1999-2000; Prous, 1991). A influência francesa na arqueologia brasileira, iniciada com a vinda de Joseph Emperaire e Annette Lamming, trazidos por Paul Rivet, traduz-se em uma arqueologia principalmente tecnicista, voltada ao estudo da ocupação mais remota do território, com a introdução de classificações e terminologias europeias aplicadas aos estudos de sambaquis, pinturas rupestres ou artefatos líticos. A influência americana, com sua tradição four-field, se faz sentir inicialmente com as pesquisas de Betty Meggers e Clifford Evans na foz do Amazonas, mas se institucionaliza mais tarde ao serem criados, durante o regime militar, com suporte do Conselho Nacional de Desenvolvimento Científico e tecnológico (CNPq) e da Smithsonian Institution, dois grandes programas de pesquisas que tinham por objetivo extensos levantamentos de campo para identificação e estudo de sítios arqueológicos (Funari, 2002; Meggers, 1985b). Sua metodologia de pesquisa envolvia a coleta de fragmentos de cerâmica por meio de escavações e prospecções de superfície (Evans \& Meggers, 1965), e a posterior análise da cerâmica segundo o método Ford, uma técnica de classificação e seriação da cerâmica (Meggers \& Evans, 1970) que tinha por objetivo criar cronologias culturais.

Essas duas vertentes da arqueologia estrangeira produziram influências duradouras no país. E, apesar de Meggers e Evans utilizarem amplamente a etnografia de grupos amazônicos para a interpretação arqueológica, nenhuma conexão, como diz Melatti (1983), foi feita entre os vestígios arqueológicos e os povos indígenas da atualidade ou aqueles já extintos, com exceção dos Tupi-Guarani.

A institucionalização da arqueologia em universidades demora a acontecer e se dá principalmente no âmbito da pós-graduação. Até o final do século XX, dos três programas que formam arqueólogos mestres e doutores no país, dois são de História e têm a arqueologia como área de concentração. O ensino da 
arqueologia em universidades é, portanto, tardio, e somente na última década, quando cresce a demanda por laudos arqueológicos, são criados diversos cursos de graduação e pós-graduação em arqueologia em todo o país (Bezerra, 2008). A novidade trazida por alguns desses cursos é a união da arqueologia com a antropologia, e a proposta "quatro campos" mencionada inclusive em um curso do Museu Nacional cujo nome é apenas Arqueologia. Esses cursos se propõem a formar antropólogos e arqueólogos em uma perspectiva interdisciplinar, promovendo uma aproximação entre essas duas disciplinas. Na pós-graduação, a tendência pode ter sido influenciada, em parte, pela coexistência dessas duas disciplinas dentro de uma mesma área na Capes; no entanto, acredito que outros fatores devem ser levados em consideração: (a) o fato de muitos arqueólogos e antropólogos brasileiros, hoje professores universitários, terem se doutorado nos Estados Unidos; (b) o fato de que os arqueólogos não trabalham apenas com vestígios de povos já desaparecidos, mas lidam com pessoas que vivem sobre e no entorno de sítios arqueológicos; (c) a necessidade de programas de educação patrimonial dentro de projetos de arqueologia de contrato; e (d) uma perspectiva reflexiva dentro da disciplina, em que se questiona o papel social do arqueólogo.

Curiosamente, esse movimento brasileiro vai na contramão dos debates atuais nos Estados Unidos, onde se assiste a uma crise dos quatro campos debatida em congressos, fóruns, periódicos e livros. Essa crise ocasionou, eventualmente, a cisão de departamentos de antropologia (Segal \& Yanagisako, 2005; Shenk, 2006). A história dos dois subcampos (antropologia cultural e arqueologia) nos Estados Unidos mostra aproximações e afastamentos em razão das mudanças de perspectivas teóricas em ambos e a adoção unilateral, em momentos cruciais, de novos paradigmas.

A institucionalização dessas disciplinas — dentro de um mesmo departamento nos Estados Unidos e em departamentos separados na Europa e no Brasil — influenciou o modo como se produziu conhecimento sobre as sociedades indígenas brasileiras. As pesquisas em etnologia e arqueologia no Brasil foram influenciadas pelas matrizes francesa e americana, levando, na maioria dos casos, a um enorme distanciamento entre etnólogos e arqueólogos. Na arqueologia amazônica, a etnologia teve e tem um papel importante, mas o contrário não é verdadeiro. Os etnólogos pouco se importam com os estudos arqueológicos, já que historicamente têm se preocupado com o "presente etnográfico".

O foco deste artigo é a relação entre arqueologia e etnologia na Amazônia do ponto de vista da primeira. Inicialmente, discuto as contribuições da etnologia à arqueologia amazônica de uma perspectiva histórica, a partir do final dos anos 1940. Em seguida, analiso a reação da ecologia histórica à ecologia cultural e 
os dados arqueológicos que indicam a extensão das transformações operadas por povos pré-colombianos nas paisagens amazônicas, com exemplos da ilha de Marajó, do Baixo Amazonas e do Acre. Finalmente, argumento que uma aproximação dos etnólogos aos arqueólogos poderia favorecer a etnologia com uma perspectiva histórica, assim como a arqueologia tem se beneficiado de perspectivas antropológicas ao longo de sua história.

\section{Arqueologia como antropologia}

Quando Lewis Binford publica, em 1962, seu artigo "Archaeology as Anthropology” (Binford, 1962), cujas raízes podem ser buscadas no movimento neoevolucionista, em suas diferentes matizes, e na crítica generalizada do histórico-culturalismo dentro da antropologia americana dos anos 1940, a arqueologia, contrariamente às suas expectativas, está mais uma vez se distanciando da antropologia social. Binford propõe que é chegada a hora de os arqueólogos contribuírem para a construção teórica na antropologia social. O artigo traz uma abordagem do registro arqueológico baseada no teste de hipóteses e em teorias de médio alcance, como parte de um movimento que ficaria conhecido como Nova Arqueologia. Binford é o porta-voz de um movimento que critica o histórico-culturalismo, que dominou a disciplina por pelo menos três décadas e que, na arqueologia, se traduz pela pressuposição de que um conjunto de artefatos com características comuns corresponde a um mesmo grupo étnico e linguístico. Trata-se do conceito de cultura arqueológica. O que se critica é uma visão normativa de cultura e propõe-se a ênfase nos processos de mudança cultural, para o que a arqueologia estaria especialmente capacitada, tendo em vista a possibilidade de examinar longos períodos de tempo.

Nos vinte anos que se seguem ao artigo seminal de Binford, assiste-se a uma mudança radical na arqueologia feita nos Estados Unidos e no mundo anglo-saxão em geral. No entanto, essa que ficaria conhecida como arqueologia processual torna-se demasiado positivista, impondo uma racionalidade capitalista sobre as sociedades estudadas, e acaba por afastar a arqueologia dos antropólogos sociais, que fazem o caminho inverso, para uma abordagem hermenêutica das culturas. A arqueologia processual, que chega tardiamente ao Brasil, nos anos 1990, nunca seria amplamente adotada, como ocorreu nos Estados Unidos. Sua influência restringe-se àqueles arqueólogos que tiveram formação no exterior ou que, mesmo no Brasil, tiveram acesso à bibliografia estrangeira.

O movimento de crítica ao histórico-culturalismo do qual a geração de Binford é fruto, contudo, teve diversas vertentes. Uma delas, a ecologia cultural neoevolucionista de Leslie White (1949) e Julian Steward (1948), influenciou 
decisivamente a arqueologia brasileira, por meio de seus alunos Betty Meggers e Clifford Evans, que formaram toda uma geração de arqueólogos brasileiros. Meggers e Evans desenvolveram suas pesquisas de doutorado na Amazônia — ela na ilha de Marajó e ele no Amapá (Meggers \& Evans, 1957) —, com o objetivo de provar, pela arqueologia, a relação entre a ecologia e o desenvolvimento cultural. Na Amazônia, onde se supunha que não teriam se desenvolvido cacicados ou estados, os jovens arqueólogos pretendiam investigar a origem da cultura marajoara e explicar o seu desaparecimento.

Curiosamente, apesar de a orientação teórica de ambos os pesquisadores situar-se no âmbito do neoevolucionismo, os trabalhos de campo e a análise dos artefatos seguiam, na prática, métodos herdados do histórico-culturalismo, pois tinham o objetivo de identificar culturas, mapeá-las no espaço e construir cronologias culturais. ${ }^{1}$ A explicação para essa aparente contradição é simples. A ecologia cultural não dependia da arqueologia, mas primariamente da análise dos aspectos físicos — solos, clima, vegetação —; dos aspectos bióticos — disponibilidade de caça, pesca e coleta — ; e dos modos de vida de povos etnográficos vivendo sob as mesmas condições. Enquanto a etnografia pintava o quadro da vida na floresta tropical (Lowie, 1948), a arqueologia mapeava no tempo e no espaço os correlatos arqueológicos desse modo de vida. Uma vez que os povos amazônicos construíam suas casas com materiais perecíveis, não havia sentido em procurá-las no registro arqueológico; tudo o que restara teriam sido os fragmentos de cerâmica. A análise da tecnologia e do estilo cerâmicos, portanto, indicaria as diferenças entre os grupos sociais e mostraria influências de uns sobre os outros, substituição de uns pelos outros nos mesmos espaços, migrações e deslocamentos pelo território.

De acordo com o mapa das áreas culturais de Steward (1948), no Brasil teriam existido apenas tribos e povos marginais (bandos ou caçadores-coletores, como foram posteriormente chamados). Os dois programas de pesquisa criados a partir da iniciativa dos norte-americanos dedicaram-se, portanto, entre 1964 e 1980, à identificação das culturas arqueológicas desses grupos em todo o território nacional.

As implicações entre arqueologia e etnologia aqui são bem claras. No entanto, a etnologia servia apenas a uma analogia generalizante. Mesmo no caso dos Tupi-Guarani, em que a cerâmica proporcionou o elo entre os grupos pré-cabralinos e aqueles conhecidos pelos relatos etno-históricos e estudos etnográficos posteriores, não foi feita nenhuma tentativa, por exemplo, de investigar outros marcadores culturais no registro arqueológico, como disposição e formato das cabanas, forma e localização das aldeias, caminhos e práticas funerárias etc. 
O artigo seminal de Meggers (1954) "Environmental limitations on the development of culture" e seu best-seller "Amazonia: man and culture in a counterfeit paradise" (Meggers, 1971), publicado no Brasil sob o título "Amazônia, a ilusão de um paraíso" (Meggers, 1977), são completamente baseados na projeção para o passado de etnografias do século XX. Sua teoria é muito simples: a floresta amazônica é um ambiente pobre em recursos para a subsistência de sociedades demograficamente densas e sociopoliticamente complexas, devido aos solos pobres, às mudanças climáticas cíclicas (El Niño) e à escassez de proteína (Meggers, 1979, 1992, 1994). Logo, os "povos de floresta tropical" que haviam sido descritos por Steward (1948) eram de fato vitoriosos por serem excepcionalmente bem adaptados a esse ambiente limitante.

Meggers (1995a) ignorou o genocídio indígena e os relatos etno-históricos em favor da ecologia cultural, assumindo que as sociedades indígenas já haviam atingido o ápice de seu desenvolvimento. Em um permanente estado de natureza, os indígenas pintados por Meggers não possuíam história, apenas diversidade cultural, medida pela diversidade da cultura material. A diversidade cultural amazônica, para ela, significava variações sobre o mesmo tema. Suas motivações não eram apenas acadêmicas ou científicas. Vários dos seus artigos foram finalizados com uma discussão sobre as implicações contemporâneas das reconstruções do comportamento sociocultural do passado. Basicamente, ela alertava para o fato de que as sociedades indígenas exauriam os recursos naturais em um ritmo bem menos acentuado do que a sociedade industrial moderna e de que qualquer forma de exploração além desses níveis levaria a desastres ambientais para toda a bacia amazônica, com consequências para o resto do mundo (Meggers 1995b, 1995c).

Para Meggers, admitir que a Amazônia pudesse ter sido transformada pelos povos indígenas seria admitir a resiliência de seus ambientes e a possibilidade de explorá-los de outras formas, que levariam à sua destruição. Ainda que a intenção de preservação da biodiversidade fosse louvável nesse caso, a negação de agência e história aos povos indígenas constituiu um autoritarismo e etnocentrismo cujas raízes podiam ser buscadas nos evolucionistas do século XIX (Noelli \& Ferreira, 2007).

A ecologia cultural de Meggers e de seus colegas das ciências naturais foi criticada desde o início por etnólogos, arqueólogos e geógrafos. William Denevan (1963) contabilizou 20 mil campos drenados na parte oeste de Beni, Amazônia boliviana, e quase $1.000 \mathrm{~km}$ de caminhos elevados feitos para deslocamento sobre zonas alagadas. Robert Carneiro (1960,1961) descreveu minuciosamente a produção e estocagem de farinha de mandioca pelos Kuikuru, que viviam 
em aldeias permanentes no Alto Xingu, contrariando as predições de Meggers. Donald Lathrap (1970a, 1970b), com base em suas pesquisas na Amazônia peruana, propôs que a Amazônia central teria sido um centro de inovação cultural (cerâmica, mandioca amarga e outros cultivos) para o continente.

Essas e outras críticas não impediram que Meggers encontrasse solo fecundo para sua arqueologia em boa parte da América Latina, incluídos aí o Brasil e a Amazônia. Em parte, isso deveu-se ao controle estrito exercido pelos arqueólogos associados a Meggers durante a ditadura militar. Em muitos lugares, e em especial na Amazônia, somente seu grupo fazia pesquisas (Roosevelt, 1991b). Simões, um ex-militar que obedecia a Meggers como seu superior hierárquico e que coordenou com ele o PRONAPABA, controlava a arqueologia Amazônica a partir do Museu Goeldi. O museu detinha inclusive o controle dos registros de sítios arqueológicos, quando o Instituto do Patrimônio Histórico e Artístico Nacional (IPHAN) ainda não tinha instalações na Amazônia. Dados contrários à teoria de Meggers eram convenientemente excluídos de publicações, pois poderiam questionar os pressupostos dos seus programas de pesquisa (Schaan, 2001).

\section{Arqueologia amazônica pós-Meggers}

As pesquisas da arqueóloga americana Anna Roosevelt tiveram importância fundamental para a virada que se inicia na arqueologia amazônica nos anos 1980. Roosevelt não é menos "ecóloga" do que Meggers, apenas inverte a lógica: onde Meggers viu um ambiente limitante, Roosevelt viu possibilidades e abundância (Roosevelt, 1980, 1991a, 1991b). Roosevelt formou-se dentro do processualismo e trouxe para a arqueologia amazônica perspectivas novas não apenas no campo da teoria, mas também dos métodos, investigando vários tipos de vestígios e estudando camadas estratigráficas em detalhe. Reabilitou observações feitas por Derby (1879) e Hartt $(1871,1874)$ no final do século XIX que Meggers havia considerado não científicas, assim como os relatos etno-históricos sobre as sociedades da várzea amazônica, que Meggers chamou de fantasiosas. Um de seus méritos foi abrir caminhos para novos pesquisadores e diferentes abordagens da história amazônica, quebrando a hegemonia do grupo de Meggers.

A arqueologia da Amazônia hoje engloba diferentes visões e perspectivas sobre o passado amazônico (Heckenberger \& Neves, 2009), mais ou menos ligados ao uso de modelos etnográficos ou à etnoarqueologia. Uma espécie de novo paradigma - a ecologia histórica (Balée, 2006, 2010; Crumley, 1994a) — tem ganhado adeptos, assim como o reconhecimento de que, à época do contato europeu, a Amazônia era habitada por povos indígenas cujos modos de vida e 
formas de organização social eram diversos (Gomes, 2007; Heckenberger \& Neves, 2009; Schaan, 2013).

\section{A ecologia histórica e as paisagens amazônicas}

O campo da ecologia histórica começou a se desenhar no final dos anos 1980, com intelectuais que focaram suas pesquisas na percepção da historicidade das paisagens transformadas por grupos humanos (Balée, 1998; Crumley, 1994b). Entretanto, no começo da década de 1960, o geógrafo William Denevan (1963, 1966) foi pioneiro na descrição e no estudo das extensas obras de terra - canais, sistemas de aquacultura, terraços, campos elevados, estradas - construídas por povos indígenas antes da conquista espanhola. Denevan foi aluno de Carl Sauer, geógrafo que assentou as bases para a geografia cultural ou histórica norte-americana na Universidade de Berkeley. O conceito de paisagem, tal como foi definido por Sauer (1969), em 1925, continha agência humana e história. Sauer constatou que eram poucos os ambientes na Terra não transformados por humanos e propôs entender a paisagem por sua qualidade orgânica, composta por elementos físicos, biológicos e culturais indissociáveis. A influência de Sauer é clara também nas pesquisas de Donald Lathrap (1977) sobre o protagonismo dos povos amazônicos na domesticação de plantas e produção da cerâmica, colocando-se contra a ecologia cultural a partir de seus estudos na Amazônia peruana. ${ }^{2}$

Durante os anos 1980, William Balée (1989b) e Darrel Posey (1985, 1989) pesquisaram práticas de manejo da floresta por parte dos Ka'apor, Kayapó e Mebengokre. Com base em inventários botânicos realizados em florestas que nasceram sobre antigas roças indígenas, Balée concluiu que a agricultura de coivara, característica do modo de produção agrícola indígena após o contato, contribuiu para o aumento da biodiversidade amazônica, produzindo o que chamou de "florestas culturais". Tais florestas antropogênicas corresponderiam a pelo menos 11,8\% das florestas de terra firme (Balée, 1989a). Esses estudos contribuíram para deitar por terra o mito de uma Amazônia prístina prévia à conquista europeia (Balée, 2006; Denevan, 1976, 1992).

A ecologia histórica define-se como uma abordagem multidisciplinar e dialética das relações entre os seres humanos e o ambiente (contrária à visão adaptativa da ecologia cultural), em que a antropologia/arqueologia possui um papel principal: "somente um punhado de disciplinas fazem a ponte entre as ciências sociais e naturais. [...] A mais compreensiva e sofisticada teoricamente é a antropologia” (Crumley, 1994a:2). Ingold (2000:189) considera a paisagem como o ponto de contato entre a arqueologia e a antropologia. Balée não acredita que a ecologia histórica represente um novo paradigma, mas propõe que ela seja um 
programa de pesquisa (no sentido dado por Lakatos, 1978) direcionado por um conjunto de postulados básicos. Esses postulados giram em torno da ideia de que todas as sociedades humanas modificaram e modificam o meio em que vivem, em interações que ocorrem em diversos contextos históricos, sem que os grupos humanos estejam programados para aumentar ou diminuir a diversidade de espécies ou outros parâmetros ambientais. As interações entre grupos humanos e paisagens devem ser estudadas como um fenômeno integral (Balée, 2006).

Crumley (1994a) alerta ainda que, mesmo quando alterações na paisagem são planejadas, frequentemente provocam consequências não intencionais ou não previstas. Há uma lição importante a ser aprendida aqui. De acordo com a ecologia histórica, os povos indígenas não são primitivos que viveram ou vivem em harmonia com uma floresta tropical virgem pouco afetada por eles (Balée, 2006). A diferença é que os distúrbios causados por povos indígenas amazônicos sobre as paisagens tropicais (desmatamento para construção de aldeias e roças, queimadas para plantio, construção de barragens, campos elevados para agricultura etc.) tiveram como consequência, na maioria dos casos, aumento da biodiversidade e melhoramento dos solos, e os impactos causados pela pecuária, agricultura mecanizada ou extração de madeira têm sido de exaustão dos solos e desertificação.

O estudo das paisagens em mudança é feito em suas dimensões histórica e espacial pela arqueologia da paisagem. As principais metodologias e as ferramentas adequadas para o estudo das paisagens amazônicas incluem interpretação de imagens de satélite, interpretação de fotografias aéreas não convencionais, prospecção aérea com pequenas aeronaves, prospecção terrestre, mapeamento com GPS e estação total, escavações, inventários florestais, pesquisa de fontes históricas, etnografia e uso de sistemas de informações geográficas (SIG) (Balée et al., 2014; Crumley, 1994b; Erickson, 1995; Schaan et al., 2010).

O uso dessas metodologias amplia o foco da pesquisa arqueológica, movendo-o do "sítio" para a paisagem (Erickson, 2010a). Isso tem implicações importantes para o estudo dos modos de vida dos povos indígenas arqueológicos, pois reconhece que as relações entre as aldeias, as estradas ou os caminhos para deslocamento, as áreas agrícolas, os locais de coletas sazonais, os canais e todas as demais atividades econômicas e sociais são tão relevantes quanto o espaço da aldeia. Sabe-se que a definição do espaço do sítio implica grande dose de arbitrariedade por parte do pesquisador, que diminui quando a escala da pesquisa aumenta, e todo e qualquer vestígio humano é considerado relevante (Dunnell, 1992). A arqueologia passa a se preocupar, portanto, com os ambientes vividos, ${ }^{3}$ os territórios construídos, tudo aquilo que está sobre o solo, não apenas o Anuário Antropológico/2013, Brasília, UnB, 2014, v. 39, n. 2: 13-44 
que se encontra sob o solo. Além disso, não estuda instantâneos de tempo, mas move-se ao longo de um tempo histórico. A arqueologia da paisagem requer um treinamento novo para o olhar do arqueólogo, que passa a ler as paisagens como palimpsestos vivos.

A falta de um olhar treinado para as paisagens e o foco exclusivo das pesquisas na cerâmica fez com que os pesquisadores dos programas de pesquisa que dominaram a arqueologia durante a ditadura militar dessem pouca importância às grandes obras construtivas dos povos indígenas pré-colombianos. Um exemplo claro disso é a classificação proposta por Ondemar Dias para os sítios encontrados por ele entre 1977 e 1980 no leste do estado do Acre. Ao se deparar com enormes valas circulares, Dias as mapeou e coletou artefatos, classificando a cerâmica encontrada em diferentes fases e reconhecendo que, em quatro dessas fases, ocorriam as "estruturas de terra". Priorizou, portanto, as pequenas diferenças entre a cerâmica encontrada nos sítios em vez de reconhecer as semelhanças entre as formas de ocupação da paisagem dadas pelas construções de terra. Uma vez que as estruturas de terra são muito padronizadas em termos de suas características construtivas, estava claro que havia uma conexão importante entre os grupos que as construíram, podendo-se supor que todas teriam sido feitas pelo mesmo povo. Ao agrupar os sítios em "fases", a partir da cerâmica, Dias minimizou as grandes obras de terra, que mudariam radicalmente sua narrativa.

\section{Modificações de paisagens amazônicas}

Há dezenas de exemplos de modificações monumentais de paisagens realizadas por povos indígenas pré-colombianos em toda a bacia Amazônica. Os exemplos já estudados incluem: campos elevados para agricultura (Guianas, Bolívia) (Erickson, 1980; Rostain, 2010), canais para irrigação de plantações (Venezuela) (Spencer, Redmond \& Rinaldi, 1994), colinas e plataformas para moradia (Ilha de Marajó/Brasil, Equador, Bolívia) (Erickson, 2006b; Roosevelt, 1991b; Rostain, 1999; Salazar, 1998), lagos artificiais, barragens e canais para criação de peixes (Ilha de Marajó/Brasil, Bolívia) (Erickson, 2000, 2001; Schaan, 2008, 2012), recintos monumentais formados por valetas geométricas (leste do Acre, sul do Amazonas/Brasil, Bolívia) (Erickson, 2010b; Schaan et al., 2010; Schaan et al., 2012b), valas defensivas (Alto Xingu e Amazonas central/Brasil) (Heckenberger et al., 2003; Moraes \& Neves 2012), caminhos elevados (Bolívia, Venezuela) (Erickson, 2006a; Spencer \& Redmond, 1998), caminhos "afundados" (Acre/Brasil, Equador) (Salazar, 1998; Schaan, 2014) e terras pretas com alto potencial agrícola (Brasil, Colômbia) (Kern et al., 2004; Mora et al., 1991; Neves et al., 2004; Woods et al., 2009). (Figura 1). 
Essas modificações foram tão intensas e profundas que, séculos após seu abandono, as estruturas e os solos construídos continuam bastante visíveis, apesar dos processos erosivos e da lixiviação causada pelas chuvas intensas da região, além do crescimento da vegetação e do desmatamento a partir do século XX. Mesmo o reaproveitamento da engenharia indígena por populações atuais (como no caso da terra preta, das colinas artificiais ou valetas) tem ocasionado a destruição lenta desse legado.

Há explicações para a resiliência dessas estruturas. Em primeiro lugar, sua construção envolveu transposição maciça de solo e inversão de camadas pedológicas, com frequente compactação do solo e ocasional adição de camadas de solo menos friável no topo. Em segundo lugar, durante o uso das estruturas, estas sofreram processo constante de limpeza, reparos, manutenção e reconstrução. Por exemplo, estradas construídas no Acre foram escavadas, retirando-se o solo mais solto junto à superfície e compactando-se o solo argiloso da base. O solo retirado foi então empilhado e compactado nas laterais da estrada, formando muretas. Ocasionalmente essas estradas eram limpas de plantas que poderiam ali crescer, e sua largura era tal (18 m ou mais) que chuvas torrenciais não teriam o poder de levar o solo da mureta de volta para o leito da estrada, cobrindo-o. Algumas dessas estradas foram abandonadas há mais de mil anos, a floresta cresceu sobre elas e, a partir dos anos 1970, foi desmatada para dar lugar a plantações ou pasto. Apesar de tudo isso, são ainda perfeitamente visíveis (Figura 2) e utilizáveis. Em terceiro lugar, a demografia atual nesses locais é menor do que a demografia pré-colombiana. Ou seja, os engenheiros indígenas estimaram a capacidade de carga de suas construções de acordo com sua demografia. As estruturas, portanto, têm a capacidade de resistir a impactos por parte de populações menores demograficamente, como são as atuais, pelo menos nos locais onde se encontram tais construções. Abaixo examinamos alguns exemplos de paisagens transformadas pela agência indígena pré-colombiana.

\section{Marajó}

No início da era cristã, surgem aldeias nas áreas de cabeceiras dos rios, no centro da ilha (Meggers \& Danon, 1988; Roosevelt, 1991b), locais de fácil obtenção de peixes no final do período de chuvas ou no inverno amazônico, quando as águas baixam e represam os cardumes. Em três séculos, as aldeias se multiplicam, à medida que começam a colocar em prática estratégias de manejo da fauna aquática, com a construção de barragens e pequenos tanques para aprisionamento dos peixes. Os viveiros de peixes permitem aumentar o período da safra e a abundância de proteínas sem precedentes leva a grande aumento Anuário Antropológico/2013, Brasília, UnB, 2014, v. 39, n. 2: 13-44 
populacional. Em poucas décadas, proliferam na ilha as plataformas de terra (tesos) que são construídas pelo acúmulo de sedimento retirado da limpeza dos lagos e os sistemas de represamento de água e peixes. A economia pesqueira se traduz em uma economia política regional e os recém-criados viveiros de peixes passam a ser dominados por elites locais, que se afirmam com base na sua ligação com ancestrais. Cada unidade política, com população entre 1.000 e 3.000 pessoas, possui dois ou três tesos principais (cerimoniais), onde são sepultadas as pessoas de prestígio e realizadas as festas e os rituais. As diferenças entre os sepultamentos indicam estratificação social (Schaan, 2004, 2012).

A partir do século IX, as elites marajoaras têm acesso a bens de prestígio, como as pedras verdes e as lâminas de machado, obtidas por meio de redes de troca suprarregionais. A ecologia construída é também uma geografia sagrada, que tem por base a relação com os ancestrais e com seres não humanos relacionados ao mundo das águas. A economia política marajoara domina o leste da ilha até o século XIV (Roosevelt, 1991b; Schaan, 2004). Por razões talvez relacionadas à chegada de grupos Aruã (Aruak) pelo norte da ilha (Meggers \& Evans, 1957), após essa data os tesos são abandonados e a população se dispersa em comunidades menores. Os povos que habitavam o Marajó e foram contatados pelo Padre Vieira no século XVII (estimados em 40 mil indígenas) não eram tupis e provavelmente não eram aruaks (Schaan, 2000). Foram exterminados pelas guerras e epidemias e relocados para missões religiosas sem que houvesse registro das línguas que falavam.

\section{Tapajó}

O povoamento da região do Baixo Amazonas inicia há 11 mil anos, mas ocorre de forma descontínua (Roosevelt, 1992; Roosevelt et al., 1996). Povos cuja cultura material indica relações com grupos que habitaram o Rio Orinoco e o Caribe passam a ocupar uma grande região entre a foz dos rios Nhamundá e Tapajós. Carvajal (1934), cronista da expedição de Francisco de Orellana que navega o Rio Amazonas em 1541, observa a grande densidade populacional, a abundância de alimentos e a belicosidade dos indígenas, que, apesar das semelhanças, teriam governos distintos ao norte e ao sul do Amazonas.

O registro arqueológico indica que os Tapajó ocuparam uma área de 4 km² onde hoje se localiza a cidade de Santarém, estendendo ainda seus domínios por uma grande área que abarca os atuais municípios de Santarém e Belterra, entre os séculos X e XVI (Schaan \& Lima, 2012). Apesar de mais conhecidos como produtores de uma cerâmica de decoração complexa, eram também exímios produtores de objetos líticos, como pingentes, furadores, facas, raspadores, 
lâminas de machado e dentes de ralador (Silva, 2012). Produziram as famosas pedras verdes, sendo peça principal de extensas redes de troca entre as elites do Baixo Amazonas, o norte da América do Sul e o Caribe à época da conquista (Boomert, 1987).

Os Tapajó são somente ocuparam a foz do Rio Tapajós, mas povoaram ambientes de rio, planalto e serras, onde as aldeias especializavam-se em diferentes estratégias econômicas, como a agricultura, a pesca e a tecelagem (Stenborg, Schaan \& Amaral-Lima, 2012), alterando significativamente a paisagem de uma

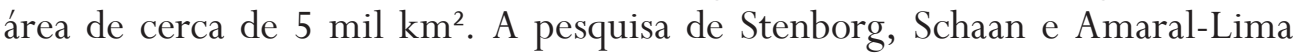
(2012) contabilizou 111 sítios arqueológicos. Dada a falta de água no planalto, ali se construíram poços de diversos tamanhos que, até meados do século XX, estavam sendo usados pela população (Nimuendajú, 2004), mas nos últimos anos foram abandonados por causa da contaminação pelos agrotóxicos usados nas plantações de soja (Schaan, 2006) (Figura 3). As práticas de cultivo e descarte de lixo geraram extensas áreas de terras pretas, um solo altamente fértil que vem sendo aproveitado e destruído pela lavoura mecanizada e pela retirada indiscriminada de terra para jardins públicos e privados (Stenborg, Schaan \& Amaral-Lima, 2012).

Descrições dos Tapajó no século XVII feitas pelo padre jesuíta João Betendorff e pelo cronista da expedição de Pedro Teixeira, Maurício de Heriarte (Bettendorff, 1990; Heriarte, 1964), têm sido usadas para preencher lacunas ou comparar esses relatos com o registro arqueológico, incluindo o estudo da cerâmica (Gomes, 2001; Macdonald, 1972; Schaan, 2012). A cerâmica produzida pelos Tapajó é de um estilo "barroco", com imagens humanas quase naturalistas e uma profusão de representações de animais como urubu-rei, jacaré, onça, jaboti, sapo, macaco, cutia e morcego, que têm possibilitado diversas classificações e interpretações (Gomes, 2002; Guapindaia, 1993; Palmatary, 1939, Roosevelt, 1988; Schaan, 2012).

Além da etno-história, usada para a interpretação arqueológica, etnologia e etnografia têm sido suporte para arqueólogos. Denise Gomes (2012:133) interpretou a iconografia tapajônica à luz do perspectivismo ameríndio, argumentando que "as representações artísticas contidas em objetos pré-coloniais amazônicos, andinos e da costa noroeste da América do Sul indicam uma unidade mitológica e cosmológica do mundo ameríndio, que ultrapassa distintas morfologias sociais e estruturas políticas”. Lathrap (1970b), com base em características decorativas e estilísticas da cerâmica, propôs que os Tapajó falassem idioma do tronco Caribe. Macdonald (1972), seguindo Lathrap, usa uma analogia etnográfica (mitologia) para interpretação da iconografia cerâmica, apontando Anuário Antropológico/2013, Brasília, UnB, 2014, v. 39, n. 2: 13-44 
semelhanças entre a iconografia da cerâmica tapajônica e a das cerâmicas de Equador e Antilhas, o que sugere relações com migrações caribes (Palmatary, 1960).

Os Tapajó sofreram violentas baixas demográficas com guerras, escravização e epidemias e tiveram que lidar com as imposições culturais e religiosas dos missionários no início da colonização, a ponto de serem considerados extintos no século XIX. Não há certeza sobre a língua falada por eles. Hoje há um movimento de etnogênese indígena importante ocorrendo no baixo curso dos rios Tapajós e Arapiuns (Beltrão, 2013).

\section{"Geoglifos" do Acre}

Entre o início da era cristã e o século $\mathrm{X}$, centenas de recintos geométricos cercados por valetas monumentais foram construídos sobre os platôs que encimam os vales dos tributários do Alto Rio Purus, no leste do estado do Acre, no sul do Amazonas e oeste de Rondônia, além do norte da Bolívia (Schaan et al., 2012b). Apesar de técnicas construtivas semelhantes empregadas para a edificação dessas estruturas sobre essa vasta região, percebem-se variações regionais que sugerem que diferentes grupos étnicos podem ter adotado tal arquitetura para construção de seus espaços de moradia, cultos, encontros e rituais. A maior parte desses locais, maiores do que um ou mais campos de futebol, foram utilizados apenas esporadicamente, a despeito do grande esforço coletivo envolvido em sua construção (Saunaluoma \& Schaan, 2012; Schaan, 2012). A geometria perfeita de muitos desses espaços sugere preocupações cosmológicas e religiosas, além de conhecimentos de matemática e engenharia (Schaan, 2010).

Até o momento, foram registrados 415 recintos no leste do estado. Um sistema de estradas foi construído para conectar diversos recintos ou para direcionar os viajantes que vinham dos rios. Aberturas para entrada e saída dos recintos disciplinavam os deslocamentos nesses espaços; divisões internas segregavam pessoas e suas atividades (Figura 2). É possível que grandes áreas no leste do Acre possuíssem apenas vegetação esparsa há dois mil anos, o que teria facilitado a construção dessas enormes estruturas. O fato de os recintos terem sido construídos nos locais mais altos e com ampla visão dos vales sugere significados religiosos, de conexão com o cosmos (Schaan et al., 2012a).

Uma vez que os recintos deixaram de ser construídos provavelmente por volta do século XIV e que a literatura que menciona contatos com os indígenas do Alto Purus é posterior ao século XVIII, não foi possível estabelecer relação direta entre os construtores dos recintos e os povos indígenas da região descritos a partir dos séculos XIX e XX. Padre Éder, missionário jesuíta que esteve em 
Llanos de Mojos no século XVIII, descreve aldeias cercadas por valetas e paliçadas, que teriam sido construídas pelos Baure com objetivos defensivos (Erickson, 2010a). Isso inicialmente abriu a possibilidade de que os recintos a oeste da Bolívia tivessem sido construídos com a mesma intenção (Pärssinen et al., 2003), hipótese que foi posteriormente abandonada, dada a ausência de outros indícios.

No final do século XIX, o coronel Antonio Labre (1889:498), em busca de uma rota comercial mais adequada entre Manaus e Bolívia, subiu o Rio Madeira e cruzou por terra uma área ocupada por grupos da família linguística takana, entre os rios Madre de Diós e Acre, onde teria encontrado uma aldeia habitada por índios que adoravam deuses geométricos e que mantinham templos no meio da floresta. O relato é bastante lacônico, mas sugere que as formas geométricas teriam algum sentido religioso para esses povos localizados em áreas onde se encontram os recintos cercados por valetas. Pirjo Virtanen (2010), antropóloga que tem trabalhado com arqueólogos no leste do estado do Acre, percebeu que desenhos de visões xamânicas dos espíritos das palmeiras por parte dos Manchineri (povo de língua aruak) são muito semelhantes ao formato dos recintos arqueológicos. As palmeiras são ainda associadas às áreas planas e altas, locais onde se localizam os sítios (Virtanen, 2010). Apesar das dificuldades em estabelecer a continuidade histórica entre os Manchineri e os construtores dos recintos, a pesquisa é bastante promissora.

\section{Considerações finais: agência indígena}

As monumentais construções de terra encontradas hoje na Amazônia constituem evidências cabais da falácia ecológico-cultural dos anos 1950. Mostram que os povos indígenas não se “adaptaram” às condições ecológicas, como propunha Meggers (1985a, 1992), mas criaram suas próprias ecologias. Isso não ocorreu de um momento para outro, mas como consequência de longos processos de crescimento demográfico e aprendizagem sobre as dinâmicas dos ambientes tropicais. Observações do clima, dos movimentos das marés do estuário, das frequências das chuvas e inundações, dos comportamentos da fauna, das características dos solos e das propriedades da flora foram essenciais para que se acumulasse experiência, para que houvesse possibilidade de predição dos eventos meteorológicos e se planejassem as intervenções, oriundas de esforços coletivos. Soluções originais foram criadas para cada problema local e, na medida em que as estratégias foram eficazes, práticas similares foram adotadas sobre vastas áreas, muitas vezes ultrapassando barreiras linguísticas e étnicas. 
Em geral, os povos indígenas atuais ou aqueles etnografados durante o século XX parecem não ter memória das construções deixadas por seus antepassados. $\mathrm{Na}$ maioria dos casos, os povos atuais não se encontram mais nos mesmos territórios, e pouca pesquisa arqueológica tem sido feita no interior de terras indígenas, com raras, mas importantes, exceções (Heckenberger, 2005, 2011; Silva, Bespalez \& Stuchi, 2011). O legado pré-colombiano, ainda assim, manifesta-se por meio de práticas culturais entre os povos indígenas atuais, obviamente, mas também entre a população não indígena. No leste da ilha de Marajó, os métodos de pesca utilizados nas cabeceiras dos rios, ao longo do século XX, mostram sobrevivência de práticas pré-colombianas, com a construção anual de barragens e represamento de peixes (Brabo, 1981; Smith, 2002). A prática pré-colombiana de esculpir e pintar símbolos da cobra grande na cerâmica, que indicou a grande importância desse animal na mitologia indígena marajoara, aparece na cosmologia dos quilombolas do Rio Gurupá, na mesma região. O assoreamento dos igarapés e a escassez de peixes, causada pelo manejo inadequado por parte de fazendeiros, que fazem plantações de açaí na beira do rio e extraem madeira indiscriminadamente, são explicados pela "fuga da cobra" que morava no rio (Rodrigues, 2013).

Nos três casos que comentei com maior detalhe (Marajó, Santarém e Acre), não há possibilidade de traçar uma continuidade histórica direta entre povos conhecidos pela arqueologia e povos atuais. Essa descontinuidade não é dada pela falta de relação genética entre os povos indígenas atuais e aqueles do passado, mas pelos efeitos devastadores da conquista europeia e da colonização. A prática do sepultamento secundário, por exemplo, tão presente entre os povos da várzea do Rio Amazonas no século XV, despareceu da região, apesar de ter sido ainda verificada entre grupos Shipibo do Peru no século XX (Chocano, 2010). Diversas práticas culturais modificaram-se pela catequização e colonização, assim como modos de vida alteraram-se drasticamente pela morte de milhares de indígenas, o que em muitos casos levou ao desaparecimento de povos inteiros. $\mathrm{O}$ violento processo de colonização do território ocasionou migrações em massa, retraimentos de povos indígenas para áreas distantes do avanço das frentes de colonização, onde vieram a compor, em muitos casos, sociedades multiétnicas e multilinguísticas.

Há que ressaltar ainda que as narrativas dos arqueólogos sobre o passado indígena, seja as que procuram levar em conta sua agência na construção das paisagens, seja as que contam a história da cerâmica, seja ainda a dos ecólogos culturais, que veem os indígenas como parte da natureza, pouco interessam aos povos indígenas na contemporaneidade. Os povos indígenas amazônicos hoje 
querem fazer suas próprias etnografias e suas próprias arqueologias, isto é, contar sua própria história (Beltrão, 2013; Green, Green \& Neves, 2003; Machado \& Beltrão, 2012; Silva, 2011; Silva, Bespalez \& Stuchi, 2011). Os etnólogos, que também produzem narrativas sobre os povos indígenas, poderiam estar mais atentos aos vestígios arqueológicos à sua volta, já que estes estão integrados às paisagens atuais e tomam parte da construção da alteridade que interessa aos antropólogos.

A profecia de Binford (1962), sobre a possibilidade de os arqueólogos produzirem teoria para a antropologia, a ser utilizada pelos demais subcampos, não se realizou, e os arqueólogos continuaram a depender dos etnólogos para construir suas hipóteses e analogias. Não vejo isso como um problema, já que me parece que tanto arqueólogos como etnólogos estão interessados em estudar "as culturas”, estejam essas no passado (dependendo da observação dos vestígios da presença humana) ou no presente (dependendo da observação e interlocução com grupos humanos). A diferença, portanto, reside mais nos métodos do que na teoria ou no objeto de estudo.

A arqueologia se realiza em duas dimensões fundamentais, espaço e tempo, que podem ser traduzidas para paisagem e temporalidade (Ingold, 2000). Os povos indígenas amazônicos deixaram mais do que os remanescentes de seus artefatos, mas produziram, como todos os povos, transformações duradouras nas paisagens, que são parte das paisagens amazônicas atuais. A leitura e a investigação das paisagens precisam ser feitas em uma perspectiva histórica; portanto, permitem acesso à história de longo termo das sociedades estudadas, estejam estas no passado ou no presente.

$\mathrm{O}$ uso indiscriminado das etnografias e das etnoarqueologias produzidas a partir do século XX, para a compreensão da Amazônia antiga, continua a ser um grande problema. Digo isso porque, de uma forma ou de outra, agência e história permanecem negadas aos povos indígenas em nome de uma suposta continuidade. Além disso, pela dificuldade já apontada neste artigo de identificar etnias no registro arqueológico, são feitas analogias com base em generalizações, ajudando na construção de uma visão homogênea dos povos indígenas — o índio "genérico" (Ramos, 2012), muito parecido com aquele da ecologia cultural.

Obviamente os povos indígenas atuais são descendentes daqueles estudados pela arqueologia, o que não deveria significar que passaram incólumes pelos 500 anos de conquista, colonialismo e república. As mudanças para os povos indígenas foram dramáticas nos últimos 500 anos, e os povos atuais são resultado ativo de sua historicidade tanto de milhares de anos como dos últimos cinco séculos. Isso precisa ser levado em conta, tanto por arqueólogos como por etnólogos.

Anuário Antropológico/2013, Brasília, UnB, 2014, v. 39, n. 2: 13-44 


\section{Agradecimentos}

Uma versão preliminar deste artigo foi apresentada no Seminário Aprofundando a Amazônia: Contribuições da Arqueologia à Etnologia, promovido pelo Laboratório de Indigenismo e Etnologia (Linde), do Departamento de Antropologia da Universidade de Brasília, para o qual fui convidada pela Profa. Dra. Alcida Ramos. Agradeço a ela e seus colegas pela agradável recepção em Brasília e pela oportunidade ímpar de discutir essas questões com antropólogos de outras áreas.

Recebido em: 18 de junho 2014

Aceito em: 10 de agosto de 2014

Denise Pahl Schaan é graduada em História pela UFRGS (1987), fez Mestrado em História/Arqueologia na PUC-RS (1996) e obteve seu PhD em Antropologia pela Universidade de Pittsburgh (2004). É professora Associada 1 da UFPA onde leciona no Programa de Pós-Graduação em Antropologia e na Faculdade de Museologia. Foi Presidente da Sociedade de Arqueologia Brasileira no biênio 2007-2009. Dedica-se à pesquisa arqueológica e antropológica na Amazônia, atuando principalmente nas seguintes áreas: história da antropologia, ecologia histórica, arqueologia da paisagem, gênero, simbolismo, cultura material, patrimônio cultural e arqueologia pública. Atualmente desenvolve projetos de pesquisa na região oriental do estado do Acre e Baixo Amazonas (Santarém, Belterra). Contato: deniseschaan@marajoara.com 


\section{Notas}

1. O método de classificação (em tipos) e seriação da cerâmica proposto por James Ford baseava-se no pressuposto evolucionista de que mudanças ocorrem de forma gradual, por força de fatores externos e ao acaso (comparavam com a deriva genética), podendo ser identificadas na cerâmica. A um conjunto de tipos identificados em determinado local davam o nome de "fase", e um conjunto de fases semelhantes poderia ser agregado em uma "tradição". Apesar de na teoria não associarem a fase a um grupo étnico-linguístico, na prática isso foi feito (Schaan, 2007).

2. Lathrap bacharelou-se em antropologia em 1950 pela Universidade de Berkeley, na Califórnia, onde foi aluno de Alfred Kroeber e Carl Sauer. Posteriormente, em 1962, obteve seu PhD em Harvard, sob a orientação de Gordon Willey.

3. Dwelling perspective, para Ingold (2000).

\section{Referências bibliográficas}

ADAMS, William Yewdale. 1998. The Philosophical Roots of Anthropology. Stanford, Calif.: CSLI. (CSLI Lecture Notes).

BALÉE, William. 1989a. "The Culture of Amazonian Forests". Advances in Economic Botany, 7:1-21. Edited by Darrel A. Posey and William Balée. Resource Management in Amazonia: Indigenous and Folk Strategies. New York: New York Botanical Garden.

1989b. "Managed Forest Succession in Amazonia: the Ka'apor Case". Advances in Economic Botany, 7:129-158.

2006. "The research Program of Historical Ecology". Annual Review of Anthropology, 35:75-98.

2009. "The four-field model of anthropology in the United States". Amazônica, $1(1): 28-53$.

2010. "Historical Ecology”. Diversity, 1(2):230-233.

(Org.). 1998. Advances in Historical Ecology. New York: Columbia University

Press.

BALÉE, William et al. 2014. "Florestas antropogênicas no Acre: inventário florestal do geoglifo 'Três Vertentes', município de Acrelândia”. Amazônica: Revista de Antropologia, 6(1):140-169. 
BARATA, Frederico. 1950. “A arte oleira dos Tapajó I: considerações sobre a cerâmica e dois tipos de vasos característicos”. Publicações do Instituto de Antropologia e Etnologia do Pará, 2:1-47.

BARRETO, Cristiana. 1999-2000. "A construção de um passado pré-colonial: uma breve história da arqueologia no Brasil”. Revista USP, 44:32-51.

BARTH, Fredrik. 2005. One Discipline, Four Ways: British, German, French, and American Anthropology. Chicago: University of Chicago Press. (The Halle Lectures).

BELTRÃO, Jane Felipe. 2013. "Pertenças, territórios e fronteiras entre os povos indígenas dos rios Tapajós e Arapiuns versus o Estado brasileiro". Antares: Letras e Humanidades, 5:5-27.

BETTENDORFF, Pe. João Felipe. 1990. Crônica dos Padres da Companhia de Jesus no Estado do Maranhão. Belém: Fundação Cultural do Pará Tancredo Neves, Secretaria de Estado da Cultura. (Lendo o Pará, 5).

BEZERRA, Marcia. 2008. "Bicho de nove cabeças: os cursos de graduação e a formação de arqueólogos no Brasil”. Revista de Arqueologia, 21(2):139-154.

BINFORD, Lewis. 1962. "Archaeology as Anthropology". American Antiquity, 28(2):217-225.

BOAS, Franz. 1911. "Changes in the Bodly Form of Descendants of Immigrants". American Anthropologist, 14:530-562.

BOAS, Franz \& STOCKING, George W. 1974. The Shaping of American Anthropology, 18831911; a Franz Boas Reader. New York: Basic Books.

BOOMERT, Arie. 1987. “Gifts of the Amazons: 'Greenstone' pendants and beads as items of ceremonial exchange in Amazonia”. Antropologica, 67:33-54.

BRABO, Maria José Carvalho. 1981. "Pescadores, geleiros, fazendeiros: os conflitos de pesca em Cachoeira do Arari”. Boletim do Museu Paraense Emílio Goeldi NS Antropologia, 77:1-22.

CARNEIRO, Robert L. 1960. "Slash-and-Burn Agriculture: a Closer Look at its Implications for Settlement Patterns". In: Anthony Wallace (ed.). Men and Cultures. Philadelphia: University of Pennsylvania Press. pp. 229-234. 
1961. "Slash-and-burn Cultivation among the Kuikuro and its Implications for Cultural Development in the Amazon Basin”. In: J. Wilbert (ed.). The Evolution of Horticultural Systems in Native South America: Causes and Consequences, a Symposium. Caracas: Sociedade de Ciencias Naturales La Salla. pp. 47-67.

CARVAJAL, Frey Gaspar de. 1934. "Discovery of the Orellana River". In: Juan Toribio de Medina (ed.). The Discovery of the Amazon According to the Account of Friar Gaspar de Carvajal and other Documents. New York: American Geographical Society. pp. 167-235.

CASTRO-FARIA, Luiz de. 1998. Antropologia: escritos exuamados. Espaço circunscrito, tempos soltos. Niterói: Editora da Universidade Federal Fluminense. v. 1.

CHOCANO, Daniel Morales. 2010. "Reconstruyendo algunos aspectos socioculturales de artefactos excavados en el bajo Ucayali - Peru”. In: Edithe Pereira \& Vera Guapindaia (ed.). Arqueologia Amazônica 1. Belém: MPEG, IPHAN, SECULT. pp. 363-402.

CRUMLEY, Carole L. 1994a. "Historical Ecology: a Multidimensional Ecological Orientation". In: (ed.). Historical Ecology: Cultural Knowledge and Changing Landscapes. Santa Fe: School of American Research Press. pp. 1-41.

(Org.). 1994b. Historical Ecology: Cultural Knowledge and Changing Landscapes. Santa Fe: School of American Research Press.

DENEVAN, William M. 1963. "Additional Comments on the Earthworks of Mojos in Northeastern Bolivia". American Antiquity, 28(4):540-545.

1966. The Aboriginal Cultural Geography of the Llanos de Mojos. Berkeley: University of California Publications.

1976. "The Aboriginal Population of Amazonia”. In: (ed.). The Native

Populations of the Americas before 1492. Madison: University of Winscosin Press.

1992. "The Pristine Myth: the Landscape of the Americas in 1492". Annals of the Association of American Geographers, 82:369-385.

DERBY, Orville. 1879. “The Artificial Mounds of the Island of Marajo”. American Naturalist, 13:224-229.

DUNNELL, Robert C. 1992. "The Notion Site”. In: Jacqueline Rossignol \& LuAnn Wandsnider (ed.). Space, Time, and Archaeological Landscapes. New York: Plenum. pp. 21-42.

ERICKSON, Clark L. 1980. "Sistemas agrícolas prehispanicos en los Llanos de Mojos". América Indígena, 40(4):731-755. 
1995. "Archaeological Methods for the Study of Ancient Landscapes of the Llanos de Mojos in the Bolivian Amazon”. In: Peter Stahl (ed.). Archaeology in the Lowland American Tropics. Cambridge: Cambridge University Press. pp. 66-95.

. 2000. "An Artificial Landscape-scale Fishery in the Bolivian Amazon”. Nature, 408:190-193.

2001. "Pre-Columbian Fish Farming in the Amazon". Expediction, 43(3):7-8.

. 2006a. "Agency, Causeways, Canals, and the Landscapes of Everyday Life in the Bolivian Amazon”. In: James E. Snead, Clark L. Erickson \& J. Andrew Darling (ed.). Landscapes of Movement: Trails, Paths, and Roads in Anthropological Perspective. Philadelphia: University of Pennsylvania Museum of Archaeology and Anthropology. pp. 204-231.

. 2006b. "The Domesticated Landscapes of the Bolivian Amazon". In: William Balée \& Clark Erickson (ed.). Time and Complexity in Historical Ecology. New York: Columbia. pp. 235-278.

. 2010a. "The Transformation of Environment into Landscape: the Historical Ecology of Monumental Earthwork Construction in the Bolivian Amazon”. Diversity, 2(1):618-652.

. 2010b. "The Transformation of Environment into Landscape: the Historical Ecology of Monumental Earthwork Construction in the Bolivian Amazon”. Diversity, 2(4):618-652.

EVANS, Clifford \& MEGGERS, Betty Jane. 1965. Guia para prospecção arqueológica no Brasil. Belém: CNPq, INPA, MPEG. (Guias, 2).

FERREIRA, Lúcio Menezes. 2007. Território primitivo: a institucionalização da arqueologia no Brasil (1870-1917). Tese de Doutorado, Universidade Estadual de Campinas.

. 2009. “'Ordenar o caos””: Emílio Goeldi e a arqueologia amazônica”. Boletim do Museu Paraense Emílio Goeldi. Ciências Humanas, 4(1):71-91.

FUNARI, Pedro Paulo. 2002. "Desaparecimento e emergência dos grupos subordinados na Arqueologia brasileira”. Horizontes Antropológicos, 8(18):131-153.

GOMES, Denise Maria Cavalcante. 2001. "Santarém: Symbolism and Power in the Tropical Forest”. In: Colin McEwan, Cristiana Barreto \& Eduardo Neves (ed.). Unknown Amazon: Culture in Nature in Ancient Brazil. London: British Museum. pp. 134-155.

2002. Cerâmica arqueológica da Amazônia: vasilhas da Coleção Tapajônica Mae-USP.

São Paulo: FAPESP/ EDUSP/Imprensa Oficial SP.

Anuário Antropológico/2013, Brasília, UnB, 2014, v. 39, n. 2: 13-44 
2007. "The Diversity of Social Forms in pre-Colonial Amazonia”. Revista de Arqueologia Americana, 25:189-225.

2012. "The Amerindian Perspectivism and the Idea of an American Aesthetics". Boletim do Museu Paraense Emílio Goeldi: Ciências Humanas, 7:1133-159.

GREEN, Lesley; GREEN, David \& NEVES, Eduardo Góes. 2003. "Indigenous Knowledge and Archaeological Science". Journal of Social Archaeology, 3(3):365-397.

GUAPINDAIA, Vera. 1993. "Fontes históricas e arqueológicas sobre os Tapajó: a coleção Frederico Barata do Museu Paraense Emílio Goeldi”. Dissertação de Mestrado, Universidade Federal de Pernambuco.

HARTMANN, Thekla (org.). 2000. Cartas do sertão de Curt Nimuendajú para Carlos Estevão de Oliveira. Lisboa: Museu Nacional de Etnologia/Assírio \& Alvim.

HARTT, Charles Frederick. 1871. "The Ancient Indian Pottery of Marajo, Brazil”. American Naturalist, 5(5):259-271.

1874. "Contributions to the Geology and Physical Geography of the Lower Amazonas". Bulletin of the Buffalo Society of Natural Science, 210-235.

HECKENBERGER, Michael J. 2005. The Ecology of Power: Culture, Place, and Personhood in the Southern Amazon, A.D. 1000-2000. New York: Routledge.

2011. "Deep History, Cultural Identities, and Ethnogenesis in the Southern Amazon”. In: Alf Hornborg \& Jonathan D. Hill (ed.). Ethnicity in Ancient Amazonia: Reconstructing Past Identities from Archaeology, Linguistics and Ethnohistory. Colorado: University Press of Colorado. pp. 57-74.

HECKENBERGER, Michael J. et al. 2003. "Amazonia 1492: Pristine Forest or Cultural Parkland?”. Science, 301:1710-1713.

HECKENBERGER, Michael J. \& NEVES, Eduardo G. 2009. "Amazonian Archaeology". Annual Review of Anthropology, 38:251-266.

HERIARTE, Maurício de. 1964. Descriçam do Estado do Maranham, Para, Corupa, Rio das Amazonas. Áustria,: Akademische Drucku. Publicado originalmente em 1663.

INGOLD, Tim. 2000. The Perception of the Environment: Essays on Livelihood, Dwelling and Skill. London: Routledge. 
KERN, Dirse et al. 2004. "Distribution of Amazonian Dark Earths in the Brazilian Amazon”. In: Bruno Glaser \& William Woods (ed.). Amazonian Dark Earths: Explorations in Space and Time. Berlin: Springer. pp. 51-75.

LABRE, Antonio. 1889. "Coronel Labre's Exploration in the Region between the Beni and the Madre de Dios Rivers and the Purus". Proceedings of the Royal Geographical Society and Monthly Record of Geography, New Monthly Series, 11(8):496-502.

LAKATOS, Imre. 1978. The Methodology of Scientific Research Programmes. Cambridge: Cambridge University Press. (His Philosophical Papers, 1).

LATHRAP, Donald W. 1970a. "La floresta tropical y el contexto cultural de Chavín”. In: R. Ravines (ed.). 100 años de arqueología en el Perú, Fuentes e Investigaciones para la Historia del Perú, 3. Lima: Instituto de Estudios Peruanos; Edición de Petróleos del Perú. p. 235-261. 1970b. The Upper Amazon. New York: Praeger.

. 1977. "Our Father the Cayman, Our Mother the Gourd: Spinden Revisited, or a Unitary Model for the Emergence of Agriculture in the New World”. In: Charles A. Reed (ed.). Origins of Agriculture. Berlin: De Gruyter Mouton. pp. 713-752.

LOWIE, Robert H. 1948. “The Tropical Forests: an Introduction”. In: J. Steward (ed.). The Tropical Forest Tribes. Washington D.C.: Smithsonian Institution. Bureau of American Ethnology. (Handbook of South American Indians, 3). Bulletin 143. pp. 1-2.

MACDONALD, Regina Harrison. 1972. The Order of Things: an Analisis of the Ceramics from Santarém, Brazil. Chicago: University of Illinois.

MACHADO, Almires Martins \& BELTRÃO, Jane Felipe. 2012. "Demarcação e conflitos: de sonhos ao oguatá guassú, a extensa caminhada em busca da(s) terra(s) isenta(s) de mal(es)”. Antropología y Derecho, 6:14-20.

MEGGERS, Betty J. 1954. "Environmental Limitations on the Development of Culture". American Anthropologist, 56(5):801-24.

. 1971. Amazonia: Man and Culture in a Counterfeit Paradise. Chicago: Aldine Atherton.

1977. Amazônia: a ilusão de um paraíso. Rio de Janeiro: Civilização Brasileira.

1979. "Climatic Oscilation as a Factor in the Prehistory of Amazonia". American Antiquity, 44(2):252-66. 
1985a. "Aboriginal Adaptation to Amazonia”. In: Ghillean T. Prance \& Thomas

E. Lovejoy (ed.). Key Environments: Amazonia. Oxford: Pergamon. pp. 307-327.

1985b. "Advances in Brazilian Archaeology, 1935-1985". American Antiquity, 50(2):364-373.

1992. "Tropical Forest Environments and Archaeology: a View from Amazonia”. In: Agamemnon Gus Pantel, Kent A. Schneider \& Gloria Loyola-Black (ed.). Environment and Archaeology. San Juan, Puerto Rico. pp. 208-222.

1994. "Archaeological Evidence for the Impact of Mega-niño Events on Amazonia during the Past Two Millennia”. Climatic Change, 28:321-338.

1995a. "Amazonia on the Eve of European Contact: Ethnohistorical, Ecological, and Anthropological Perspectives”. Revista de Arqueologia Americana, 8:91-115.

1995b. "Archaeological Perspectives on the Potential of Amazonia for Intensive Exploitation”. In: Toshie Nishizawa \& Juha Uitto (ed.). The Fragile Tropics of Latin America: Sustainable Management of Changing Environments. Tokyo: United Nations University Press. pp. 68-93.

. 1995c. "Judging the Future by the Past: the Impact of Environmental Stability on Prehistoric Amazonian Populations”. In: Leslie E. Sponsel (ed.). Indigenous Peoples and the Future of Amazonia: an Ecological Anthropology of an Endangered World. Tucson: The Unviversity of Arizona Press. pp. 15-43.

MEGGERS, Betty J. \& DANON, Jacques. 1988. "Identification and Implications of a Hiatus in the Archeological Sequence on Marajo Island, Brazil”. Journal of Washington Academy of Sciences, 78(3):245-253.

MEGGERS, Betty J. \& EVANS, Clifford. 1957. Archeological Investigations at the Mouth of the Amazon. Washington, D.C.: Smithsonian Institution Bureau of American Ethnology; U.S. Government Printing Office (Bulletin 167).

1970. Como interpretar a linguagem da cerâmica: manual para arqueólogos. Washington, DC: Smithsonian Institution.

MELATTI, Julio Cezar. 1983. A antropologia no Brasil: um roteiro. Brasília: Universidade de Brasília. (Série Antropologia).

MELTZER, David J. 1985. "North American Archaeology and Archaeologists, 18791934”. American Antiquity, 50(2):249-260. 
MORA, Santiago et al. 1991. Cultivars, Anthropic Soils and Stability: a Preliminary Report of Archaeological Research in Araracuara, Colombian Amazonia. Pittsburgh: University of Pittsburgh. MORAES, Claide de Paula \& NEVES, Eduardo Góes. 2012. "O ano 1000: adensamento populacional, interação e conflito na Amazônia central”. Amazônica, 4(1):122-148.

NEVES, Eduardo et al. 2004. "The Timing of Terra Preta Formation in the Central Amazon: Archaeological Data from Three Sites”. In: Bruno Glaser \& William Woods (ed.). Amazonia Dark Earths: Explorations in Space and Time. Berlin: Springer. pp. 125-134.

NIMUENDAJÚ, Curt. 2004. In Pursuit of a Past Amazon: Archaeological Researches in the Brazilian Guyana and in the Amazon Region. Gotenborg: Elanders Infologistik.

NOELLI, Francisco Silva \& FERREIRA, Lúcio Menezes. 2007. "A persistência da teoria da degeneração indígena e do colonialismo nos fundamentos da arqueologia brasileira”. História, Ciências, Saúde-Maguinhos, 14(4):1239-1264.

PALMATARY, Helen Constance. 1939. “Tapajó Pottery”. Etnologiska Studier, 8:1-136.

. 1960. "The Archaeology of the Lower Tapajós Valley, Brazil”. Transactions of the American Philosophical Society, New Series, 50(3):243p.

PÄRSSINEN, Martti et al. 2003. "Geometrically Patterned Ancient Earthworks in the Rio Branco Region of Acre, Brazil”. Renvall Institute Publications, 14:97-133.

PEIXOTO, Fernanda. 1998. "Lévi-Strauss no Brasil: a formação do etnólogo". Mana, 4(1):79-107.

POSEY, Darrell A. 1985. "Indigenous Management of Tropical Forest Ecosystems: the Case of the Kayapó Indians of the Brazilian Amazon”. Agroforestry Systems, 3:139-158.

. 1989. "Alternatives to Forest Destruction: Lessons from the Mebengokre Indians". The Ecologist, 19(6):241-244.

PROUS, André. 1991. Arqueologia brasileira. Brasília: UnB.

RAMOS, Alcida Rita. 2012. “The Politics of Perspectivism”. Annual Review of Anthropology, 41:481-494.

RODRIGUES, Eliana Teles. 2013. “'A gente faz a varja”: territorialidade, estratégias de uso de recursos, identidade e conflitos na Ilha de Marajó, Pará”. Tese de Doutorado, Universidade Federal do Pará.

ROOSEVELT, Anna C. 1980. Parmana: Prehistoric Maize and Manioc Subsistence along the Amazon and Orinoco. New York: Academic Press. 
1988. “Interpreting Certain Female Images in Prehistoric Art”. In: Virginia E. Miller (ed.). The Role of Gender in Precolumbian Art and Architecture. Chicago: University Press of America. pp. 1-34.

. 1991a. "Determinismo ecológico na interpretação do desenvolvimento social indígena da Amazônia”. In: Walter Alves Neves (ed.). Origens, adaptações e diversidade biológica do homem nativo da Amazônia. Belém, PA: MPEG/CNPq/SCT/PR. pp. 103-141.

1991b. Moundbuilders of the Amazon: Geophysical Archaeology on Marajo Island, Brazil. San Diego: Academic Press.

1992. "Arqueologia Amazônica”. In: Manuela Carneiro da Cunha (ed.). História dos Índios no Brasil. São Paulo: Fapesp; Cia. das Letras; SMC. pp. 53-86.

ROOSEVElT, Anna C. et al. 1996. "Paleoindian Cave Dwellers in the Amazon: The Peopling of America”. Science, 272:372-384.

ROSTAIN, Stéphen. 1999. "Secuencia arqueólogica en montículos del valle del Upano en la Amazonia ecuatoriana”. Bulletin de l'Institut Français d'Études Andines, 28(1):53-89.

. 2010. "Pre-Columbian Earthworks in Coastal Amazonia”. Diversity, 2(3):331-352.

SALAZAR, Ernesto. 1998. "De vuelta al Sangay: investigaciones arqueológicas en el alto Upano, Amazonia Ecuatoriana”. Bulletin de l'Institut Français d'Études Andines, 27(2):213-240.

SANTOS, Ricardo Ventura. 2010. "Mestiçagem, degeneração e a viabilidade de uma nação: debates em antropologia física no Brasil (1870-1930)”. In: Marcos Chor Maio \& Ricardo Ventura Santos (ed.) Raça como questão: história, ciência e identidades no Brasil. Rio de Janeiro: Faperj/Fiocruz. pp. 83-108.

SAUER, Carl Ortwin. 1969. “The Morphology of Landscape (1925)”. In: J. Leighly (ed.). Land and Life: a Selection from the Writings of Carl Ortwin Sauer. Berkeley: University of California Press. pp. 315-350.

SAUNALUOMA, Sanna \& SCHAAN, Denise Pahl. 2012. "Monumentality in Western Amazonian Formative Societies: Geometric Ditched Enclosures in the Brazilian State of Acre”. Antiqua, 2(1). Disponível em: <http://www.pagepress.org/journals/index.php/ antiqua/article/view/antiqua.2012.e1>.

SCHAAN, Denise Pahl. 2000. "Evidências para a permanência da cultura marajoara à época do contato europeu”. Revista de Arqueologia, 12/13:23-42. 
. 2001. “Os dados inéditos do Projeto Marajó (1962-1965)”. Revista do Museu de Arqueologia e Etnologia, 11:141-164.

. 2004. "The Camutins Chiefdom: Rise and Development of Complex Societies on Marajó Island, Brazilian Amazon”. Ph.D. Dissertation, University of Pittsburgh.

. 2006. Diagnóstico do patrimônio arqueológico na área de influência da rodovia BR-163 - Trecho Santarém-Rurópolis. Belém: UFPA. 39 p. (inédito).

. 2007. "Uma janela para a história pré-colonial da Amazônia: olhando além — e apesar — das fases e tradições”. Boletim do Museu Paraense Emílio Goeldi. Série Antropologia, 2(1):77-89.

. 2008. “The Nonagricultural Chiefdoms of Marajó Island”. In: Helaine Silverman \& William Isbell (ed.). Handbook of South American Archaeology. New York: Springer. pp. 339-357.

. 2010. "Paisagens da Amazônia Ocidental”. In: Denise P. Schaan, Alceu Ranzi e Antonia Damasceno Barbosa (ed.). Paisagens da Amazônia Ocidental. Rio Branco: GKNoronha. pp. 13-17.

2012. Sacred Geographies of Ancient Amazonia: Historical Ecology of Social Complexity. Walnut Creek, CA: Left Coast Press. (New Frontiers in Historical Ecology, 3).

. 2013. "Cronologia das transformações das paisagens amazônicas". III Encuentro Internacional de Arqueología Amazónica, Quito, Ecuador.

2014. Estudo dos sítios arqueológicos tipo Geoglifo localizados nos estados do Acre, Amazonas e Rondônia com vistas a instruir processo de Tombamento: relatório final. Belém: Universidade Federal do Pará.

SCHAAN, Denise Pahl et al. 2010. "Construindo paisagens como espaços sociais: o caso dos geoglifos do Acre”. Revista de Arqueologia, 23(1):30-41.

SCHAAN, Denise Pahl \& LIMA, Anderson Marcio Amaral. 2012. "A grande expansão geográfica dos Tapajó”. In: . (ed.). Arqueologia, patrimônio e multiculturalismo na beira da estrada: pesquisando ao longo das rodovias Transamazônica e Santarém-Cuiabá, Pará. Belém: GK Noronha. pp. 17-36.

SCHAAN, Denise Pahl et al. 2012a. "Arquitetura monumental na Amazônia Ocidental: os sítios tipo geoglifo no estado do Acre”. In: W. F. Morales \& F. P. Moi (ed.). Tempos ancestrais. São Paulo: Annablume. pp. 191-216. 
SCHAAN, Denise Pahlet al. 2012b. "New Radiometric Dates for pre-Columbian (2000-700 B.P.) Earthworks in Western Amazonia, Brazil”. Journal of Field Archaeology, 37(2):132-142.

SCHWARCZ, Lilia Moritz. 1993. O espetáculo das raças: cientistas, instituições e questão racial no Brasil (1870-1930). São Paulo: Companhia das Letras.

SEGAL, Daniel Alan \& YANAGISAKO, Sylvia Junko. 2005. Unwrapping the Sacred Bundle: Reflections on the Disciplining of Anthropology. Durham: Duke University Press.

SHENK, Mary K. 2006. "Models for the Future of Anthropology". Anthropology News, 47(1):6-7.

SILVA, Fabíola. 2011. "Arqueologia como tradução do passado no presente". Amazônica, $3(2): 260-267$.

SILVA, Fabíola Andrea; BESPALEZ, Eduardo \& STUCHI, Francisco Forte. 2011. "Arqueologia colaborativa na Amazônia: terra indígena Kuatinemu, rio Xingu, Pará”. Amazônica, 3(1):32-59.

SILVA, Tallyta Suenny Araujo da. 2012. Entre mentes, gestos e pedras: cadeia operatória lítica no sítio Porto de Santarém. Relatório Final (PIBIC), Universidade Federal do Pará.

SMITH, Nigel. 2002. Amazon Sweet Sea: Land, Life, and Water at the River's Mouth. Austin: University of Texas Press.

SPENCER, Charles \& REDMOND, Elsa. 1998. "Prehispanic Causeways and Regional Politics in the Llanos de Barinas, Venezuela”. Latin American Antiquity, 9(2):95-110.

SPENCER, Charles S.; REDMOND, Elsa M. \& RINALDI, Milagro. 1994. "Drained Fields at la Tigra, Venezuelan Llanos: a Regional Perspective”. Latin American Antiquity, 5(2):119-143.

STENBORG, Per. 2009. "Points of Convergence, Routes of Divergence: Some Considerations Based on Curt Nimuendajú's Archaeological Work in the Santarém-Trombetas Area and at Amapá”. In: Neil L. Whitehead \& Stéphanie W. Alemán (ed.). Anthropologies of Guayana: Cultural Spaces in Northeastern Amazonia. Tucson: University of Arizona Press. pp. 55-73.

STENBORG, Per, SCHAAN, Denise \& AMARAL-LIMA, Marcio. 2012. "Precolumbian Land Use and Settlement Pattern in the Amazon Region, Lower Amazon”. Amazônica, 4(1):222-250. 
STEWARD, Julian H. 1948. "The Tropical Forest Tribes”. In: (ed.). Handbook of South American Indians. Washington D.C.: Smithsonian Institution. Bureau of American Ethnology. Bulletin 143. v. 3.

TORRES, Heloísa Alberto. 1930. “Cerâmica de Marajó”. Kosmos, 1(1): 13-15.

. 1937. "Contribuição para o estudo da proteção ao material arqueológico e etnográfico no Brasil”. Revista do SPHAN, 1:9-30.

. 1940. A arte indígena da Amazônia. Rio de Janeiro: Imprensa Nacional. (Publicações do SPHAN, 6).

TYLOR, Edward B. 1871. Primitive Culture: Researches into the Development of Mythology, Philosophy, Religion, Art, and Custom. London: J. Murray.

VIRTANEN, Pirjo Kristiina. 2010. “Constancy in Continuity: Native Oral History, Iconography and the Earthworks of the Upper Purus”. In: Alf Hornborg \& Jonathan D. Hill (ed.). Ethnicity in Ancient Amazonia: Reconstructing Past Identities from Archaeology, Linguistics, and Ethnohistory. Boulder: University Press of Colorado.

WHITE, Leslie. 1949. The Science of Culture: a Study of Man and Civilization. Farrar: Straus and Giroux.

WOODS, William et al. 2009. Amazonian Dark Earths: Wim Sombroek's vision. Berlin: Springer. 


\section{Resumo}

A etnologia e a arqueologia desenvolveram-se no Brasil no século XX como campos distintos do conhecimento. A institucionalização dessas disciplinas nas universidades, a partir principalmente de modelos europeus, influenciou o modo como se produziu conhecimento sobre as sociedades indígenas brasileiras. $\mathrm{Na}$ arqueologia amazônica, a etnologia teve e tem um papel importante na interpretação do registro arqueológico, ao passo que o contrário não é verdadeiro. Este artigo centra-se na relação entre arqueologia e etnologia na Amazônia. É analisado o uso que a abordagem ecológico-cultural na arqueologia faz dos dados etnográficos e as reações contrárias vindas do campo da ecologia histórica, com exemplos de transformações pré-colombianas da paisagem na ilha de Marajó, no Baixo Amazonas e no Acre. Finalmente, argumenta-se que uma colaboração entre etnólogos e arqueólogos poderia favorecer a etnologia com uma perspectiva histórica, assim como a arqueologia tem se beneficiado de diversas perspectivas antropológicas ao longo de sua história.

Palavras-chave: Arqueologia, Amazônia, Paisagem, Povos indígenas.

\section{Abstract}

Ethnology and archaeology developed in Brazil as separate fields of knowledge. The institutionalization of these fields inside universities based on European models influenced the production of knowledge on indigenous societies in Brazil. Ethnology has played an important role in the interpretation of the archeological record in Amazonia, but the opposite is not true. This article focuses on the interplay between archaeology and ethnology in Amazonia. It analyses the uses of ethnographic analogy by cultural ecology, and the reactions from the field of historical ecology, with examples of pre-Columbian landscape transformations on Marajó Island, Lower Amazon and Acre. Finally, it is argued that collaboration between ethnologists and archaeologists could provide ethnology with a historical perspective, in the same way archaeology has benefitted from various anthropological perspectives along its history.

Keywords: Archaeology, Amazonia, Landscape, Indigenous peoples. 


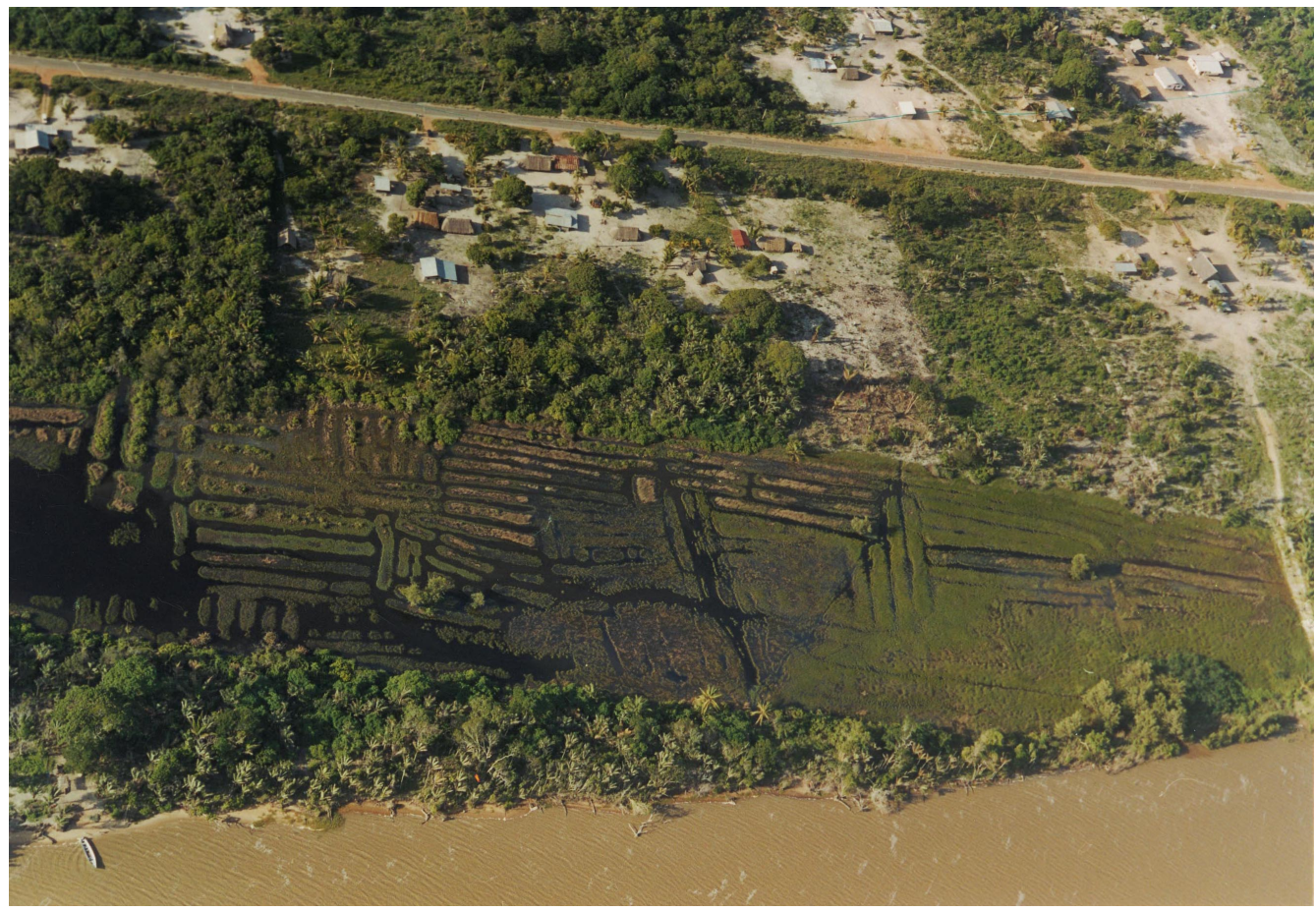

Figura 1 - Campos agrícolas elevados de Piliwa, costa ocidental da Guiana Francesa (Foto de S. Rostain)

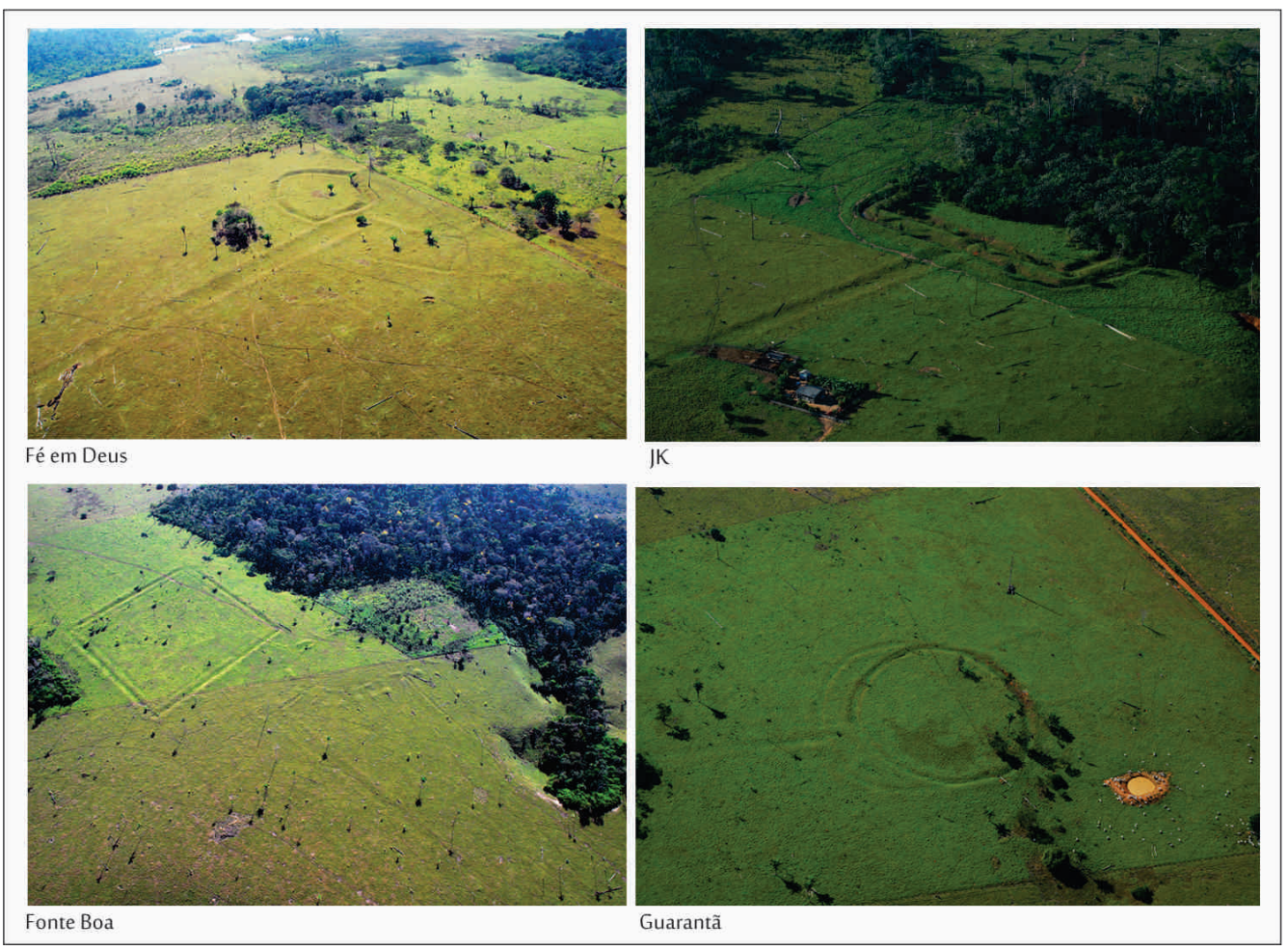

Figura 2 - Estradas e recintos pré-colombianos no leste do estado do Acre (Fotos acervo grupo de pesquisa Geoglifos da Amazônia) 


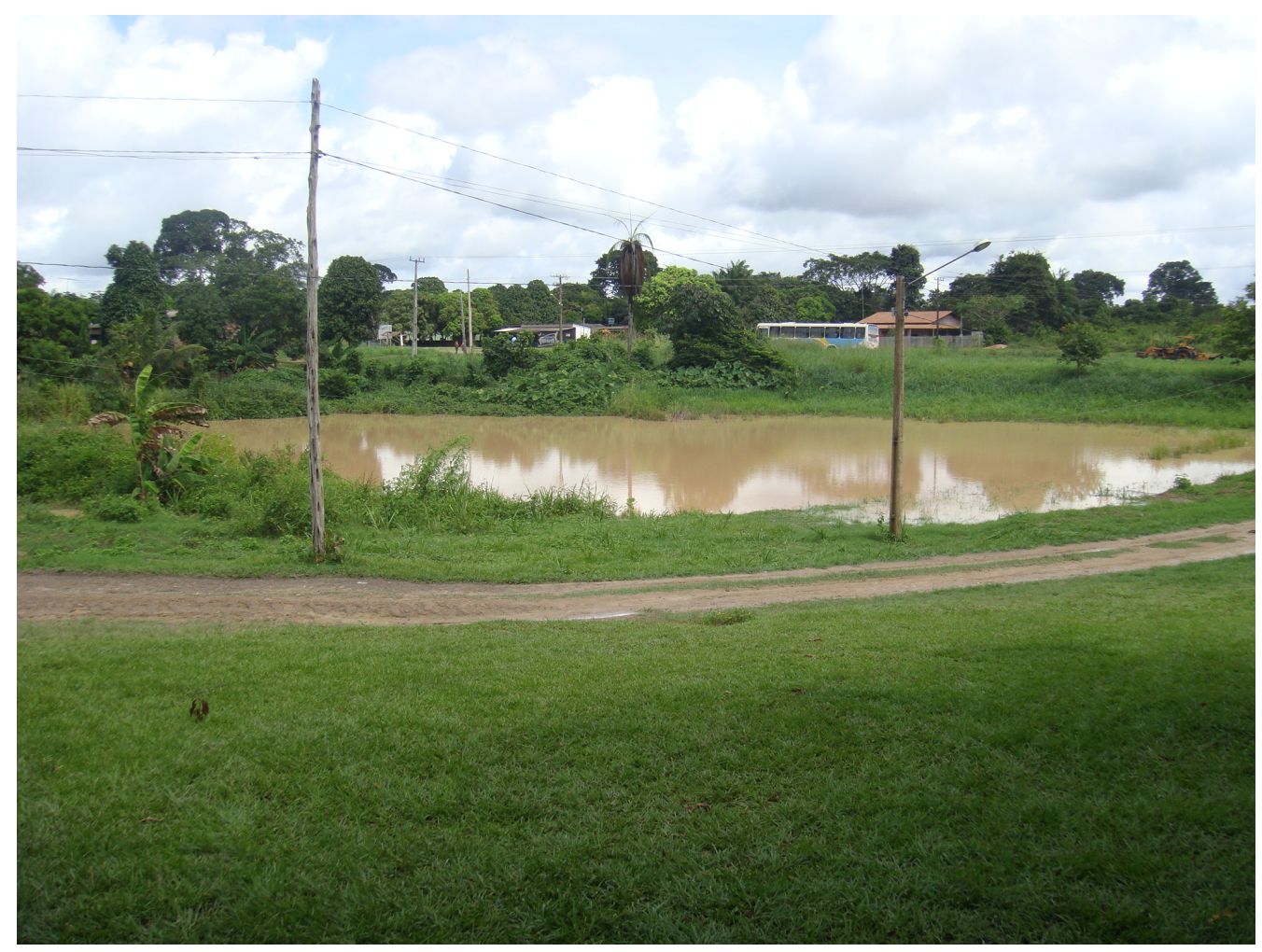

Figura 3 - "Poço" pré-colombiano na comunidade Cipoal, Santarém/PA (Foto D. Schaan) 